\title{
Maternal serum lactate dehydrogenase level and adverse pregnancy outcomes in women with hypertensive disorder of pregnancy at a tertiary care centre: a retrospective study
}

\author{
Disha Ajila, Aishwarya Raja*, Pradeep Ganiga
}

Department of Obstetrics and Gynecology, AJ Institute of Medical Sciences, Mangalore, Karnataka, India

Received: 25 November 2021

Accepted: 10 December 2021

\section{*Correspondence:}

Dr. Aishwarya Raja,

E-mail: aishwarya264@gmail.com

Copyright: (C) the author(s), publisher and licensee Medip Academy. This is an open-access article distributed under the terms of the Creative Commons Attribution Non-Commercial License, which permits unrestricted non-commercial use, distribution, and reproduction in any medium, provided the original work is properly cited.

\section{ABSTRACT}

Background: Hypertensive disorder of pregnancy affect 6-8\% of all pregnancies, contributing immensely to maternal morbidity and mortality. Thus, presence of lactate dehydrogenase (LDH) signifies tissue damage and haemolysis. The aim of the study was to correlate LDH levels with blood pressure ranges and maternal and foetal outcome in women with gestational hypertension, pre-eclampsia.

Methods: This retrospective study was conducted in the department of obstetrics and gynaecology of AJ Institute of Medical Sciences and Research Centre, Mangalore for a period of 1 year (January 2020 to January 2021). Based on the eligibility criteria, 52 hypertensive pregnant women were enrolled as cases.

Results: Mean \pm SD period of gestation at delivery was lowest $(34.57 \pm 1.39$ weeks) for pregnant women with S. LDH levels>800 IU/l, whereas with S. LDH<00 IU/l delivered at around 37 weeks of gestation. Mean Apgar scores were lowest for the babies born to hypertensive pregnant women $>800 \mathrm{IU} / \mathrm{l}$, mean \pm SD Apgar scores at the end of $1 \mathrm{~min}, 5$ minutes and $10 \mathrm{~min}$ were $4.42 \pm 0.79,4.75 \pm 2.26$ and $5.50 \pm 2.65$ respectively.

Conclusions: It can be concluded that S. LDH has the potential to be considered as a screening tool or predictor of the outcome of pregnancy in women with hypertensive disorders of pregnancy. However, studies of larger magnitude may be required to confirm the presence and the strength of association of S. LDH levels with pregnancy outcome.

Keywords: Lactic, Dehydrogenase, Preeclampsia, Eclampsia, Maternal outcome

\section{INTRODUCTION}

Hypertensive disorders are reported in $8-10 \%$ of the pregnant women in India. ${ }^{1}$ This condition, forms a complex triad when occurs with hemorrhage and infection; and is responsible for around $10-15 \%$ of the maternal deaths. $^{2,3}$ Around $19 \%$ i.e.; almost one in every five maternal death in developing countries (India included) is because of hypertensive disorders in pregnancy (HDP). ${ }^{4}$

Once the hypertension sets in, endothelial dysfunction is bound to occur via various pathways; and this in turn causes mild to moderate microangiopathy of target organs i.e.; liver/kidney/brain/lungs/placenta may be damaged.
Also, in some cases, this may lead to disseminated intravascular coagulation and death. ${ }^{1,5-7}$

Because of microangiopathy, an enzyme named lactate dehydrogenase (LDH), which catalyzes the conversion of lactate to pyruvate and back, is released excessively into the serum. ${ }^{6}$ Thus, presence of LDH signifies tissue damage and haemolysis. ${ }^{8}$

This knowledge of pathophysiology may be exploited to predict the complications in pregnant hypertensive women i.e. there is a probability of S. LDH being a screening tool for pregnant women. This, if true, will help in improving the antenatal care and hence the pregnancy outcome. 
With this background, the study was conducted with the objective to determine the association of S. LDH levels in third trimester of hypertensive pregnant women with fetomaternal morbidity and mortality

\section{METHODS}

This hospital based retrospective study was conducted in the department of obstetrics and gynaecology of AJ Institute of Medical Sciences and Research Centre, Kuntikana, Mangalore for a period of 1 year (January 2020 to January 2021) after obtaining ethical clearance from the Institutional Ethical Committee. Study participants included all the hypertensive pregnant women who were admitted to the hospital for delivery. Timeframe sampling was adopted i.e.; all the hypertensive pregnant women who delivered in the study setting between January 2020 and January 2021 were considered as potential study participants. They were screened for eligibility criteria, which were as follows:

\section{Inclusion criteria}

All the pregnant women with gestational age of $\geq 28$ weeks, diagnosed with H.D.P. i.e.; hypertensive disorder during pregnancy (diagnosed according to the National Institute for Health and Care Excellence i.e.; NICE guidelines of antenatal care) who delivered in the study setting between January 2020 and January 2021.9

\section{Exclusion criteria}

All the patients with following criteria were excluded- (a) multifetal gestation; (b) pregnant women with other medical records like- (1) diabetes mellitus type 2; (2) SARS CoV-19; (3) renal disease/s; (4) liver disease/s; (5) cardiovascular disease/s; (6) thyroid disorder/s; and (7) hyperuricemia.

After screening, 52 pregnant women were found eligible for participation in the study. Their details were taken from the Hospital Records, maintained at the Medical Records Department of the Institute, after obtaining permission from the concerned administrative authorities. Study variables included antenatal factors (women's age at the time of conception, parity, blood pressure measurement, serum lactate dehydrogenase value), intranatal factors (period of gestation at the time of delivery, mode of delivery), maternal complications and details related to the fetal morbidity (birth-weight, Apgar scores) and fetal mortality (death during perinatal period). For values of blood pressure and serum lactate dehydrogenase, third trimester of the pregnancy was used as reference. If more than one value was recorded in the case file, then the antenatal measurement which was closest to the delivery was taken.

S. LDH levels, an important parameter in the study were grouped in three categories: (i) <600 IU/l; (ii) 600-800 IU/1 and (iii) >800 IU/1.10 Perinatal deaths included stillbirths and death within first seven days of life. ${ }^{10}$

\section{Statistical analysis}

Data entry was done in Microsoft Excel version 2016 and analysis was done in trial version of 'IBM SPSS Statistics 26' software. Qualitative variables (S. LDH groups, parity, mode of delivery, perinatal deaths etc) were summarized as frequencies and percentages. Continuous variables (S. LDH level, blood pressure, Apgar score) were summarized in the form of mean values with their standard deviation. To compare the three S. LDH groups with respect to continuous variables, one way ANOVA (Analysis of variance) was used. Post Hoc Tukey's Honest Significant Difference test was applied for pairwise comparison of variables with significant ANOVA test. To determine the association between S. LDH groups and perinatal outcome, Pearson's Chi-square test of significance was applied.

\section{RESULTS}

As shown in Table 1, out of the 52 study participants, most of them (26 out of 52 i.e.; $50 \%$ ) had their S. LDH<600 IU/l. Another 23\% had S. LDH measuring >800 IU/l.

Table 2 shows that, almost half of the hypertensive mothers who were primigravida $(51.4 \%)$ as well as multigravida (47.1\%) had their S. LDH levels<600 IU/1. Among primigravid mothers, remaining proportion was almost equally distributed between the 2 serum LDH groups. Among remaining multigravida mothers, 35.3\% had S. LDH levels between 600-800 IU/1 and $17.6 \%$ had $\mathrm{S} . \mathrm{LDH}>800 \mathrm{IU} / 1$. However, this difference in S. LDH groups among mothers with different parity status were not statistically significant.

Table 3 shows that $15.4 \%$ of the pregnant women with S. $\mathrm{LDH}<600 \mathrm{IU} / 1,14.3 \%$ of the pregnant women with $\mathrm{S}$. LDH $600-800$ IU/l and $41.7 \%$ of the pregnant women with $\mathrm{S}$. $\mathrm{LDH}>800 \mathrm{IU} / 1$ had their systolic blood pressure $\geq 160$ $\mathrm{mm}$ of $\mathrm{Hg}$. Likewise, none of the pregnant women with S. LDH $<600 \mathrm{IU} / 1,21.4 \%$ of the pregnant women with S. LDH $600-800$ IU/1 and $16.6 \%$ of the pregnant women with $\mathrm{S}$. $\mathrm{LDH}>800 \mathrm{IU} / 1$ had their diastolic blood pressure $\geq 110$ $\mathrm{mm}$ of $\mathrm{Hg}$. However, these differences in the proportions were not statistically significant.

Table 4 shows that mean \pm SD age of study participants in pregnant women with their third trimester S. LDH $<600$ IU/1, 600-800 IU/1 and > $800 \mathrm{IU} / 1$ are $25.31 \pm 1.67$ years, $26.79 \pm 1.42$ years and $26.17 \pm 2.33$ years respectively. Mean \pm SD systolic blood pressure was highest $149.50 \pm 24.18 \mathrm{~mm}$ of $\mathrm{Hg}$ among the pregnant women with $\mathrm{S}$. LDH>800 IU/l. Also, mean \pm SD diastolic blood pressure was highest $96.43 \pm 10.08 \mathrm{~mm}$ of $\mathrm{Hg}$ among the pregnant women with S. LDH between $600 \mathrm{IU} / 1$ and $800 \mathrm{IU} / 1$. Mean \pm SD period of gestation at delivery was lowest $34.57 \pm 1.39$ weeks for pregnant women with S. LDH 
levels $>800$ IU/l, whereas pregnant women with S. LDH $<800$ IU/1 delivered at around 37 weeks of gestation. On running ANOVA test, difference in means among the three groups of pregnant women was statistically significant ( $p$ value $<0.001$ ) only for period of gestation at the time of delivery. Post-hoc analysis was done for this variable.

Table 5 shows post-hoc analysis for difference between the mean periods of gestation at delivery among the three groups of hypertensive pregnant women. Mean period of gestation for pregnant women with S. LDH>800 IU/1 varied significantly ( $\mathrm{p}$ value $<0.001$ ) with mean period of gestation for pregnant women with S. LDH of 600-800 IU/l and with mean period of gestation for pregnant women with S. LDH<600 IU/l. There was no statistically significant difference between the mean periods of gestation among the pregnant women with $\mathrm{S}$. $\mathrm{LDH}<600$ IU/1 and with S. LDH of 600-800 IU/1.

From Table 6, it is understood that almost half $(53.8 \%)$ of the pregnant women with S. LDH<600 IU/L, three-fourths (78.6\%) of the pregnant women with S. LDH of 600-800 IU/l and all $(100.00 \%)$ of the pregnant women with $\mathrm{S}$. LDH $>800$ IU/l delivered vaginally. Difference in these proportions is statistically significant. Table 7 shows that mean \pm SD birth-weight of the newborns is lowest $2.16 \pm 0.39 \mathrm{~kg}$ among those hypertensive pregnant women with S. LDH>800 IU/l. Similarly, mean Apgar scores were lowest for the babies born to hypertensive pregnant women $>800$ IU/l i.e.; in this group of women, mean \pm SD Apgar scores at the end of $1 \mathrm{~min}, 5 \mathrm{~min}$ and $10 \mathrm{~min}$ were $4.42 \pm 0.79,4.75 \pm 2.26$ and $5.50 \pm 2.65$ respectively. Also, ANOVA test showed statistically significant difference between the mean Apgar scores among the three groups. Hence, post-hoc analysis was done.

As shown in Table 8, mean Apgar scores at $1 \mathrm{~min}, 5 \mathrm{~min}$ and $10 \mathrm{~min}$ of babies born to hypertensive pregnant women with $\mathrm{S}$. LDH $>800 \mathrm{IU} / \mathrm{l}$ was significantly different ( $\mathrm{p}$ value $<0.05$ ) from those with $\mathrm{S}$. LDH of $600-800 \mathrm{IU} / \mathrm{l}$ and from those with $\mathrm{S}$. LDH $<600 \mathrm{IU} / \mathrm{l}$. There was no statistically significant difference between the mean Apgar scores of the babies born to hypertensive pregnant women with S. LDH<600 IU/1 and with S. LDH of 600-800 IU/l. Table 9 shows that most of the babies born to hypertensive pregnant women with S. LDH $<800 \mathrm{IU} / 1(92.3 \%$ and $71.4 \%$ of the babies born to mothers with $\mathrm{S}$. LDH $<600 \mathrm{IU} / 1$ and 600-800 IU/1 respectively) survived for more than 7 days of life, as opposed to only $50 \%$ of the newborns of hypertensive mothers with $\mathrm{S}$. LDH>800 IU/1 who survived. This difference in the proportions is statistically significant i.e.; as the mothers' third trimester S. LDH levels increase, proportion of perinatal mortality increases.

\section{Maternal complications}

Maternal complications such as placental abruption, postpartum hemorrhage, HELLP syndrome, renal failure, cerebrovascular accidents etc. were seen in $7.7 \%$ of the hypertensive pregnant women (2 out of 26) with S. $\mathrm{LDH}<600 \mathrm{IU} / \mathrm{l}$, in $28.6 \%$ of the hypertensive pregnant women (4 out of 14) with S. LDH of 600-800 IU/1 and in $33.3 \%$ of the hypertensive pregnant women (4 out of 12) with S. LDH>800 IU/l. However, this difference in proportions is not statistically significant (Chi square test $\mathrm{p}$ value $=0.103)$. None of the study participants faced mortality.

Table 1: Distribution of study participants as per S. LDH levels.

\begin{tabular}{|c|c|c|c|}
\hline S. no. & S. LDH (IU/I) & Frequency & Percentage \\
\hline 1 & $<600$ & 26 & 50.00 \\
\hline 2 & $600-800$ & 14 & 26.90 \\
\hline 3 & $>800$ & 12 & 23.10 \\
\hline & Total & 52 & 100.00 \\
\hline
\end{tabular}

Table 2: Distribution of study participants as per parity and S. LDH levels.

\begin{tabular}{|c|c|c|c|c|c|c|c|}
\hline \multirow{2}{*}{ Variables } & & \multicolumn{3}{|c|}{ S. LDH level in IU/I [frequency (row percentage)] } & \multirow{2}{*}{$\chi^{2}$} & \multirow{2}{*}{ df } & \multirow{2}{*}{ P value } \\
\hline & & $<600(\%)$ & $600-800(\%)$ & $>800(\%)$ & & & \\
\hline \multirow{3}{*}{ Parity } & Primigravida & $18(51.4)$ & $8(22.9)$ & $9(25.7)$ & \multirow{3}{*}{1.024} & \multirow{3}{*}{2} & \multirow{3}{*}{0.59} \\
\hline & Multigravida & $8(47.1)$ & $6(35.3)$ & $3(17.6)$ & & & \\
\hline & Total & $26(50.0)$ & 14 (26.9) & $12(23.1)$ & & & \\
\hline
\end{tabular}

Note: S. LDH: Serum lactate dehydrogenase; $\chi^{2}$ : Chi-square test of significance; df: degrees offreedom; $p$ value: considered significant if $<0.05$.

Table 3: Distribution of study participants as per blood pressure and S. LDH levels.

\begin{tabular}{|c|c|c|c|c|c|c|c|}
\hline \multirow{2}{*}{ Variables } & & \multicolumn{3}{|c|}{ S. LDH level in IU/I [frequency (row percentage)] } & \multirow{2}{*}{$\chi^{2}$} & \multirow{2}{*}{ df } & \multirow{2}{*}{ P value } \\
\hline & & $<600(\%)$ & $600-800(\%)$ & $>800(\%)$ & & & \\
\hline \multirow{2}{*}{$\begin{array}{l}\text { SBP } \\
(\mathrm{mmHg})\end{array}$} & $90-139$ & $8(30.8)$ & $4(28.6)$ & $4(33.3)$ & \multirow{2}{*}{4.904} & \multirow{2}{*}{4} & \multirow{2}{*}{0.297} \\
\hline & $140-159$ & $14(53.8)$ & $8(57.1)$ & $3(25.0)$ & & & \\
\hline
\end{tabular}

Continued. 


\begin{tabular}{|c|c|c|c|c|c|c|c|}
\hline \multirow{2}{*}{ Variables } & & \multicolumn{3}{|c|}{ S. LDH level in IU/l [frequency (row percentage)] } & \multirow{2}{*}{$\chi^{2}$} & \multirow{2}{*}{ df } & \multirow{2}{*}{$P$ value } \\
\hline & & $<600(\%)$ & $600-800(\%)$ & $>800(\%)$ & & & \\
\hline & $\geq 160$ & $4(15.4)$ & $2(14.3)$ & $5(41.7)$ & & & \\
\hline \multirow{3}{*}{$\begin{array}{l}\text { DBP } \\
(\mathrm{mmHg})\end{array}$} & Total & $26(100.00)$ & $14(100.00)$ & $12(100.00)$ & \multirow{3}{*}{7.936} & \multirow{3}{*}{4} & \multirow{3}{*}{0.094} \\
\hline & $60-89$ & $8(30.8)$ & $2(14.3)$ & $5(41.7)$ & & & \\
\hline & $90-109$ & $18(69.2)$ & $9(64.3)$ & $5(41.7)$ & & & \\
\hline
\end{tabular}

Note: S. LDH: Serum Lactate Dehydrogenase; SBP: Systolic blood pressure; DBP: Diastolic blood pressure; mmHg: millimeters of Mercury; $\chi^{2}$ : Chi square test of significance; df: degrees of freedom; $p$ value: considered significant if $<0.05$.

Table 4: Mean \pm SD of age, period of gestation and blood pressure among study participants grouped based on S. LDH.

\begin{tabular}{|c|c|c|c|c|c|c|}
\hline & \multirow{2}{*}{ Variables } & \multicolumn{3}{|c|}{$\begin{array}{l}\text { S. LDH level in IU/I [frequency (row } \\
\text { percentage)] }\end{array}$} & \multirow{2}{*}{$\begin{array}{l}\text { F test } \\
\text { statistic }^{\#}\end{array}$} & \multirow[t]{2}{*}{ P value } \\
\hline & & $<600(\%)$ & $600-800(\%)$ & $>800(\%)$ & & \\
\hline 1. & Age (years) & $25.31 \pm 1.6$ & $26.79 \pm 1.42$ & $26.17 \pm 2.33$ & 3.301 & 0.05 \\
\hline 2. & $\begin{array}{l}\text { Period of gestation at } \\
\text { delivery (weeks) }\end{array}$ & $37.52 \pm 0.89$ & $37.0 \pm 1.21$ & $34.57 \pm 1.39$ & 30.074 & $<0.001 *$ \\
\hline 3. & $\mathrm{SBP}(\mathrm{mmHg})$ & $143.85 \pm 11.93$ & $136.00 \pm 21.47$ & $149.50 \pm 24.18$ & 1.857 & 0.167 \\
\hline 4. & DBP $(\mathrm{mmHg})$ & $88.62 \pm 9.65$ & $96.43 \pm 10.08$ & $90.67 \pm 13.81$ & 2.387 & 0.103 \\
\hline
\end{tabular}

Note: S. LDH: Serum lactate dehydrogenase; SBP: Systolic blood pressure; DBP: Diastolic blood pressure; mmHg: millimeters of Mercury; ${ }^{\#} \mathrm{~F}$ test statistic: got by one-way Analysis of Variance (ANOVA) test; *p value: considered significant if $<0.05$.

Table 5: Pairwise comparisons for means of period of gestation at delivery among studyparticipants grouped based on S. LDH levels: post-hoc Tukey's honest significant difference test.

\begin{tabular}{|c|c|c|c|}
\hline \multirow{2}{*}{$\begin{array}{l}\text { Variables with significant } \\
\text { ANOVA test }\end{array}$} & \multicolumn{3}{|c|}{$\begin{array}{l}\text { Difference between the means (p value) among the pairs grouped based on } \\
\text { S. LDH levels (in IU/I) }\end{array}$} \\
\hline & '<600' vs '600-800' & $'<600^{\prime}$ vs ' $>800$ ' & '600-800' vs ' $>800$ ' \\
\hline $\begin{array}{l}\text { Period of } \\
\text { gestation at delivery (weeks) }\end{array}$ & $0.46(0.436)$ & $2.96(<0.001 *)$ & $2.50\left(<0.001^{*}\right)$ \\
\hline
\end{tabular}

Note: $\mathrm{p}$ value: considered significant if $<0.05$.

Table 6: Mode of delivery of study participants as per S. LDH levels.

\begin{tabular}{|c|c|c|c|c|c|c|c|}
\hline \multirow{2}{*}{ Variables } & & \multicolumn{3}{|c|}{ S. LDH level in IU/l [frequency (row percentage)] } & \multirow{2}{*}{$\chi^{2}$} & \multirow{2}{*}{ df } & \multirow{2}{*}{ P value } \\
\hline & & $<600(\%)$ & $600-800(\%)$ & $>800(\%)$ & & & \\
\hline \multirow{3}{*}{$\begin{array}{l}\text { Mode of } \\
\text { delivery }\end{array}$} & $\begin{array}{l}\text { Vaginal } \\
\text { delivery }\end{array}$ & $14(53.8)$ & $11(78.6)$ & $12(100.00)$ & \multirow{3}{*}{9.035} & \multirow{3}{*}{2} & \multirow{3}{*}{$0.011^{*}$} \\
\hline & $\begin{array}{l}\text { Caesarean } \\
\text { section }\end{array}$ & $12(46.2)$ & $3(21.4)$ & 0 & & & \\
\hline & Total & $26(100.00)$ & $14(100.00)$ & $12(100.00)$ & & & \\
\hline
\end{tabular}

Note: S. LDH: Serum lactate dehydrogenase; $\chi^{2}$ : Chi square test of significance; df: degrees of freedom; $p$ value: considered significant if $<0.05$.

Table 7: Mean \pm SD of birth-weight and Apgar scores among study participants grouped based on S. LDH.

\begin{tabular}{|c|c|c|c|c|c|c|}
\hline \multirow{2}{*}{$\begin{array}{l}\text { S. } \\
\text { no. }\end{array}$} & \multirow{2}{*}{ Variables } & \multicolumn{3}{|c|}{ S. LDH level in IU/l (mean \pm SD) } & \multirow{2}{*}{$\begin{array}{l}\text { F test } \\
\text { statistic }^{\#}\end{array}$} & \multirow{2}{*}{$P$ value } \\
\hline & & $<600(\%)$ & $600-800(\%)$ & $>800(\%)$ & & \\
\hline 1. & Birth-weight (kg) & $2.44 \pm 37$ & $2.36 \pm 0.17$ & $2.16 \pm 0.39$ & 2.990 & 0.073 \\
\hline 2. & Apgar score at $1 \mathrm{~min}$ & $6.31 \pm 0.62$ & $6.29 \pm 0.47$ & $4.42 \pm 0.79$ & 41.542 & $<0.001 *$ \\
\hline 3. & Apgar score at $5 \mathrm{~min}$ & $7.23 \pm 0.59$ & $7.07 \pm 0.27$ & $4.75 \pm 2.26$ & 20.300 & $<0.001 *$ \\
\hline 4. & Apgar score at $10 \mathrm{~min}$ & $7.85 \pm 0.37$ & $7.21 \pm 0.58$ & $5.50 \pm 2.65$ & 13.101 & $<0.001 *$ \\
\hline
\end{tabular}

Note: S. LDH: Serum lactate dehydrogenase; F test statistic: got by one-way Analysis of variance (ANOVA) test; SD: Standard deviation; *-p value: considered significant if $<0.05$. 
Table 8: Pairwise comparisons for means of Apgar scores among study participants grouped based on serum lactate dehydrogenase levels: post-hoc Tukey's honest significantdifference test.

\begin{tabular}{|c|c|c|c|}
\hline \multirow{2}{*}{$\begin{array}{l}\text { Variables with significant ANOVA } \\
\text { test }\end{array}$} & \multicolumn{3}{|c|}{$\begin{array}{l}\text { Difference between the means (p value) among the pairs grouped based on } \\
\text { S. LDH levels (in IU/) }\end{array}$} \\
\hline & '<600' vs '600-800' & ${ }^{\prime}<600$ ' vs ' $>800$ ' & '600-800' vs '> $>800$ ' \\
\hline Apgar score at 1 min & $0.02(0.994)$ & $1.89(<0.001 *)$ & $1.87(<0.001 *)$ \\
\hline Apgar score at $5 \mathrm{~min}$ & $0.16(0.910)$ & $2.48(<0.001 *)$ & $2.32(<0.001 *)$ \\
\hline Apgar score at $10 \mathrm{~min}$ & $0.63(0.324)$ & $2.35(<0.001 *)$ & $1.71(0.005 *)$ \\
\hline
\end{tabular}

Note: $\mathrm{p}$ value: considered significant if $<0.05$.

Table 9: Association between perinatal death and S. LDH levels.

\begin{tabular}{|c|c|c|c|c|c|c|c|}
\hline \multirow{2}{*}{ Variables } & & \multicolumn{3}{|c|}{ S. LDH level in IU/l [frequency (row percentage)] } & \multirow{2}{*}{$\chi^{2}$} & \multirow{2}{*}{ df } & \multirow{2}{*}{ P value } \\
\hline & & $<600(\%)$ & $600-800(\%)$ & $>800(\%)$ & & & \\
\hline \multirow{3}{*}{$\begin{array}{l}\text { Perinatal } \\
\text { death }\end{array}$} & Absent & $24(92.3)$ & $10(71.4)$ & $6(50.0)$ & \multirow{3}{*}{8.605} & \multirow{3}{*}{2} & \multirow{3}{*}{$0.014 *$} \\
\hline & Present & $2(7.7)$ & $4(28.6)$ & $6(50.0)$ & & & \\
\hline & Total & $26(100.00)$ & $14(100.00)$ & $12(100.00)$ & & & \\
\hline
\end{tabular}

Note: S. LDH: Serum lactate dehydrogenase; $\chi^{2}$ : Chi square test of significance; df: degrees of freedom; $\mathrm{p}$ value: considered significant if $<0.05$.

In the present study, almost two-fifth of the hypertensive study participants had higher levels of S. LDH i.e.; $23.10 \%$ had S. LDH>800 IU/l. This is similar (30\%) to study conducted by Kharb et al in Haryana in 2019. ${ }^{11}$ Another study conducted by Mehta et al in 2019 in Jharkhand had $>50 \%$ hypertensive women with $\mathrm{S}$. LDH> 800 IU/1. ${ }^{12}$ Mean age of the study participants was 25.90 years and around $67.3 \%$ of the study participants were primigravida. These findings are very similar to a study conducted by Hak et al in 2015 in Jammu, where mean age was 25.75 years and $75 \%$ of the pregnant women had conceived for the first time. ${ }^{13}$ Also, in this study conducted by Hak et al in 2015 , mean period of gestationat the time of delivery was found to be 36 weeks and 33 weeks for groups with $\mathrm{S}$. LDH<800 IU/1 and with $\mathrm{S}$. LDH $>800$ IU/l respectively. ${ }^{13}$ The present study showed that the period of gestation at the time of delivery in both the groups was extended by 1 week i.e.; hypertensive pregnant women with S. LDH $<800 \mathrm{IU} / 1$ delivered at around 37 weeks and those with $\mathrm{S}$. LDH $>800 \mathrm{IU} / 1$ delivered at around 34 weeks. This increment in the period of gestation may be due to better control of blood pressure and timely management that happened over the span of 5 years. In the present study, $66.7 \%$ of the pregnant women with S. LDH>800 IU/l had severe pre- eclampsia as similar to $62 \%$ in a study conducted by Mehta et al in Jharkhand in 2019 and $75 \%$ in a study conducted by Kharb et al in Haryana in $2019 .{ }^{11,12}$

None of the women in the present study whose S. LDH was >800 IU/1 underwent Caesarean section, whereas in the study conducted by Hak et al in 2015 in Jammu, caesarean sectionrate was $30 \%$ and in another study conducted by Murthy et al in 2019 in Karnataka, all the pregnant women with S. LDH>800 IU/1 underwent caesarean section. ${ }^{13}$ This evident difference in the proportion of caesarean section rate requires to be evaluated further. Maternal S. LDH is a potential predictor of Apgar scores according to the present study as the study established statistically significant association between mean Apgar scores and maternal S. LDH levels.

With respect to deaths in the new-borns, Perinatal mortality rate (PNMR) in the present study was 50\% among the children born to mothers with $\mathrm{S}$. $\mathrm{LDH}>800$ IU/l. This is double as compared to the study conducted by Mehta et al in Jharkhand in 2019, where PNMR among children bornto pregnant women with $\mathrm{S}$. LDH>800 IU/1 was $26 \% .^{12}$ The PNMR proportion is very high in these 2 studies, as compared to 5\% PNMR, as found in the study conducted by Kharb et al in Haryana in 2019. Further contrasting to this is the study conducted by Murthy et al in 2019 in Karnataka, where perinatal mortality rate was reported to be $45 \%$ amongthe new-borns of hypertensive pregnant women with S. LDH>800 IU/1. ${ }^{14}$ None of these studies reported mortality among the babies born to hypertensive mothers with S. LDH<800 IU/l. However, the present study and the study conducted by Bairwa et al in 2018 in Rajasthan reported deaths at S. LDH levels of around $600 \mathrm{IU} / \mathrm{l}$ as well. ${ }^{15}$ Now, though there are various studies in this regard, most of their statistical significance is not proven unlike the present study where the association between S. LDH levels and PNMR is shown to be significant. Strength of the study is that, it provides a basic framework for planning and conducting further studies. This study is limited by short duration, and hence the small sample size. Hence, a larger study with cross-sectional or prospective study design may be planned for collection of all the variables in detailed manner.

\section{CONCLUSION}

Hypertension during pregnancy is an important medical condition whose prevalence is on the rise owing to increasing pregnancies at extreme age-groups, changing 
lifestyle etc. Management of pregnant women with this condition is still a challenge to the obstetrician's skills. Taking into consideration the statistically significant association of S. LDH with period of gestation at the time of delivery and with Apgar scores in the present study, it can be concluded that S. LDH has the potential to be considered as a screening tool or predictor of the outcome of pregnancy in women with hypertensive disorders of pregnancy. However, studies of largermagnitude may be required on order to determine and further confirm the presence and the strengthof association of S. LDH levels with pregnancy outcome.

\section{ACKNOWLEDGMENTS}

The authors wish to acknowledge the contributions of the resident doctors who voluntarily assisted in retrieving data from case notes and hospital records.

Funding: No funding sources

Conflict of interest: None declared

Ethical approval: The study was approved by the Institutional Ethics Committee

\section{REFERENCES}

1. National Health Portal of India. Preeclampsia, 2021. Available at: https://www.nhp.gov.in/disease/gynaecologyandobst etrics/preeclampsia\#: :text=In\%20India\%2C\%20the $\% 20$ incidence $\% 20$ of,the $\% 20$ study $\% 20$ population $\% 2$ 0in\%20India. Accessed on 01 December 2021.

2. ACOG Practice Bulletin Summary. Gestational Hypertension and Preeclampsia, Number 222. Obstet Gynecol. 2020;135(6):1492-5.

3. Duley L. Maternal mortality associated with hypertensive disorders of pregnancy in Africa, Asia, Latin America and the Caribbean. $\mathrm{Br} \mathrm{J}$ Obstet Gynaecol. 1999;99(7):547-53.

4. WHO. Trends in maternal mortality: 1990 to 2010. Geneva: WHO; 2012.

5. Dharmashankar K, Widlansky ME. Vascular endothelial function and hypertension: insights and directions. Curr Hypertens Rep. 2010;12(6):448-55.
6. Kant RH, Mir N, Sarwar S, Gupta S, Najeeb R. Role of maternal serum lactate dehydrogenase as a biochemical marker in pre-eclampsia. IOSR J Dental Med Sci. 2015;14(7):12-9.

7. Jain S, Pinto B, Kalra N, Dhawan V. Relationship Between Inflammation and Endothelial Dysfunction in Essential Hypertension. J Hypertension. 2015;33(2):4.

8. Butt AA, Michaels S, Greer D, Clark R, Kissinger P, Martin DH. Serum LDH level as a clue to the diagnosis of histoplasmosis. AIDS Read. 2002;12(7):317-21.

9. NICE. Overview- Hypertension in pregnancy: diagnosis and management, 2019. Available at: https://www.nice.org.uk/guidance/ng133. Accessed on 01 December 2021.

10. Dave A, Maru L, Jain A. LDH (Lactate Dehydrogenase): A Biochemical Marker for the Prediction of Adverse Outcomes in Pre-eclampsia and Eclampsia. J Obstet Gynaecol India. 2016;66(1):23-9.

11. Kharb S, Bhandari N, Gupta S. Lactate dehydrogenase and maternal and perinatal outcome in preeclamptic women. Archives Med Health Sci. 2019;7(2):163.

12. Mehta M, Parashar M, Kumar R. A Serum LDH: a prognostic factor in pre-eclampsia. Int $\mathbf{J}$ Reprod Contracept Obstet Gynecol 2019;8:2792-8.

13. Hak J, Nisa N, Gupta S. LDH Levels in Pregnancy and its Association with Severity of the Disease and Fetomaternal Outcome in Pre-eclampsia and Eclampsia. J Med Educ Res. 2015;17(3):110-3.

14. Murthy KD, Siddiqui D. To study the correlation of serum lactate dehydrogenase (LDH) levels in women with preeclampsia on maternal and perinatal outcome. Obsgyne Review: J Obstet Gynecol. 2019;5(1):19-25.

15. Bairwa R, Iqbal S. Serum lactate dehydrogenase (LDH) level in mild and severe preeclampsia as a prognostic marker. Int J Reprod Contracept Obstet Gynecol. 2018;7:3969-74.

Cite this article as: Ajila D, Raja A, Ganiga P. Maternal serum lactate dehydrogenase level and adverse pregnancy outcomes in women with hypertensive disorder of pregnancy at a tertiary care centre: a retrospective study. Int J Reprod Contracept Obstet Gynecol 2022;11:44-9. 